\title{
Development of New Endovascular Devices for Aneurysm Treatment
}

\author{
Zhen Yu Jia, ${ }^{\text {a,b }}$ Hai Bin Shi, ${ }^{\mathrm{b}}$ Shigeru Miyachi, ${ }^{\mathrm{c}}$ Sun Moon Hwang, ${ }^{\mathrm{a}}$ Jae Jon Sheen, ${ }^{\mathrm{a}}$ Yun Sun Song, ${ }^{\mathrm{a}}$ \\ Joong Goo Kim, ${ }^{a}$ Deok Hee Lee, ${ }^{a}$ Dae Chul Suh ${ }^{a}$
}

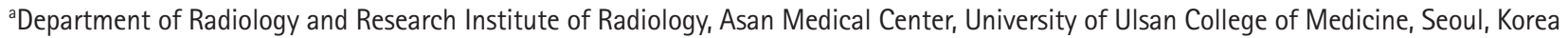
${ }^{b}$ Department of Radiology, The First Affiliated Hospital of Nanjing Medical University, Nanjing, China

'Neuroendovascular Therapy Center, Aichi Medical University, Nagakute, Japan
\end{abstract}

\begin{abstract}
Since the first use of the Guglielmi detachable coil system for cerebral aneurysm embolization in 1990, various endovascular methods have been developed to treat large numbers of aneurysms. The main strategic and technical modifications introduced to date include balloon-assisted coil embolization, stent-assisted coil embolization, flow diverters, and flow disrupters. The development and introduction of such devices have been so persistent and rapid that new devices are being approved worldwide even before the earlier ones become available in some countries. However, even if some patient populations may possibly benefit from earlier introduction of new devices, the approval authorities should balance the available evidence of the safety and effectiveness of novel devices. This review aims to provide an overview of the recent innovations in endovascular treatment of cerebral aneurysms and a brief review of market access policies and regulations for importing high-risk medical devices, such as those used for endovascular aneurysm management, which correspond to class III devices, as defined by the U.S. Food and Drug Administration. We focus on the current situation in Korea and compare it with that in other Asian countries, such as China and Japan.
\end{abstract}

Keywords Aneurysm; Device approval; Endovascular; Korea
Correspondence: Dae Chul Suh Department of Radiology and Research Institute of Radiology, Asan Medical Center, University of Ulsan College of Medicine, 88 Olympic-ro 43-gil, Songpa-gu, Seoul 05505, Korea Tel: +82-2-3010-5944

Fax: +82-2-476-0090

E-mail: dcsuh@amc.seoul.kr

Received: September 22, 2016

Revised: December 28, 2017

Accepted: January 1, 2018

\section{Introduction}

Intracranial saccular aneurysms occur in $1 \%$ to $2 \%$ of the general population and account for approximately $80 \%$ to $85 \%$ of non-traumatic subarachnoid hemorrhages. ${ }^{1}$ A meta-analysis of 33 studies showed a case fatality rate of $8.3 \%$ to $66.7 \%$ in patients with subarachnoid hemorrhage. ${ }^{2}$ Endovascular treatment of intracranial aneurysms emerged in the 1990s with the advent of the Guglielmi detachable coil system (Boston Scientific, Natick, MA, USA), ${ }^{3}$ and the use of coil embolization to treat aneurysms has substantially increased after the publication of the results of the International Subarachnoid Aneurysm Trial $\left(\right.$ ISAT) ${ }^{4,5}$ and the International Study of Unruptured Intracranial Aneurysms (ISUIA). ${ }^{6}$ The ISAT results ${ }^{4}$ showed that disability or death at 1-year follow-up occurred in 30.9\% of patients treated surgically, whereas this figure was only $23.5 \%$ in patients treated with coil embolization. Similarly, the ISUIA trial showed the overall morbidity and mortality at 1 year was 12.6\% (if no prior history of subarachnoid hemorrhage) for surgical clipping and $9.8 \%$ for endovascular coiling. ${ }^{6}$ Importantly, crossover, where $>50 \%$ patients needing aneurysm treatment undergo coiling rather than clipping, is reported to have occurred in the 


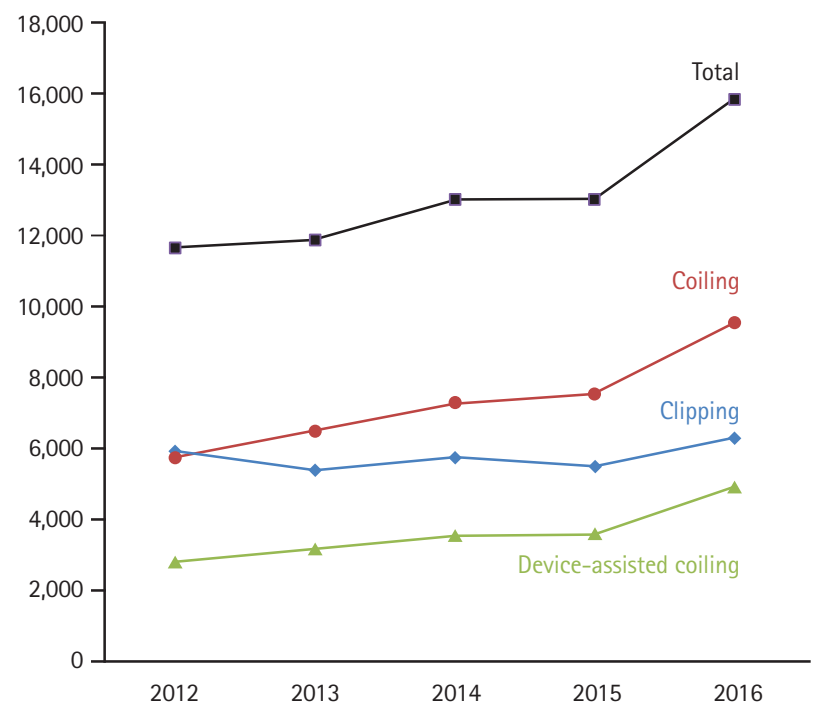

Figure 1. Current case trends in Korea with data provided by the Health Insurance Review and Assessment Services (HIRA). Number of patients treated with device-assisted coiling and coiling in total (including coiling alone and device-assisted coiling) increase together. Crossover to coiling from clipping occurred in 2013. There has been no significant change in patient number of clipping probably due to higher level of insurance payment for surgical procedure compared to that for non-invasive treatment in Korea.

European countries in the 1990s, in the United States in 2004, ${ }^{7.8}$ and in Korea in 2013 (Figure 1). ${ }^{9}$

Although endovascular aneurysm treatment options have proven to have better outcomes than clipping for both ruptured and unruptured aneurysms, treating complex aneurysms using conventional coiling is challenging. Specifically, although balloon-assisted or stent-assisted coiling for wide-neck aneurysms shows better occlusion rates and lower recurrence, ${ }^{10-12}$ the recanalization rate of treated large/giant aneurysms can be as high as $18.2 \% .^{13,14}$ This observation led to the development of flow diverter, which achieves aneurysm occlusion by endoluminal reconstruction of the vessel wall of the parent artery. ${ }^{15,16}$ The flow diverter is a stent-like structure that redirects blood flow away from the aneurysm depending on its metalto-vessel wall coverage ratio, thereby promoting aneurysm thrombosis. Flow diverters have been successfully used for treating wide-neck, giant, fusiform, and blister-like aneurysms. ${ }^{15-17}$ Recent device innovations have made previously difficult or untreatable aneurysms easy to manage, and novel device designs are being frequently reported. ${ }^{18-23}$

Medtronic (Minneapolis, MN, USA), Stryker (Kalamazoo, MI, USA), Codman Neuro (Los Gatos, CA, USA), and MicroVention (Aliso Viejo, CA, USA) are four large manufactures of neuroendovascular devices. All these companies are located in the USA. The U.S. Food and Drug Administration (FDA) of the USA usually requires adequate evidence from prospective clinical trials to approve new medical devices, whereas in the European Union (EU), clinical trials of effectiveness are generally not required for approval of most devices. ${ }^{24}$ Therefore, many new medical devices are usually approved faster in the EU than in the USA. ${ }^{24}$ Korea, China, and Japan are considered to be pivotal East Asian countries that play a prominent role in the field of neurointervention; although these countries have a substantial market for medical devices, they rely heavily on imported medical devices. ${ }^{25-27}$ Despite EU and FDA approval, the pre-market access process for a new medical device in the Asian market may be required because ethnic difference may exist in Asian people. Approval authorities usually evaluate high risk devices through a strict regulatory process to detect potential risk arising from devices and to safeguard patient safety. ${ }^{13,24,28-31}$

In this article, we review the status of new device development for endovascular treatment of aneurysms and then provide a brief review of market access policies and regulations for importing high-risk medical devices in Korea, China, and Japan.

\section{Methods}

We searched the Pubmed, Google, and Google Scholar databases for new devices designed for treating intracranial aneurysms on May 31, 2017. The search terms "aneurysm," "intracranial aneurysm," "cerebral aneurysm," "brain aneurysm," "endovascular," and "device" in "AND" and "OR" combinations were used. Publications or reports published in the last 5 years were preferentially selected, but classically important reports published previously were also included. Improvements in devices, including detachable coils, compliant balloons, and stents, that are routinely used for intracranial aneurysm embolization were excluded. Further, as flow diverters are widely employed for treating wide-necked, giant, fusiform, and blister-like intracranial aneurysms and are used in clinical practice in Asian countries, they were also excluded in this review. ${ }^{15-17}$ Information gathered from the search included pictures and manufacturing and marketing details of each device; these were then matched with the latest published research results and on-going clinical trials for that device.

We obtained information on the administrative processes for new medical device import and approval from the recently updated website of the Korean Ministry of Food and Drug Safety (MFDS), China Food and Drug Administration (CFDA), and Pharmaceuticals and Medical Devices Agency (PMDA) of Japan. Executives and experts from medical companies responsible for registering such devices and obtaining approval for them and physicians using these devices in all three countries were also consulted to verify the content presented in this review. Data 
Table 1. Information on devices available for intracranial aneurysm management

\begin{tabular}{|c|c|c|c|c|c|c|}
\hline $\begin{array}{l}\text { Device } \\
\text { picture }\end{array}$ & Device name & Manufacture & $\begin{array}{l}\text { CE Mark and } \\
\text { FDA approval }\end{array}$ & $\begin{array}{l}\text { Korea/China/ } \\
\text { Japan market }\end{array}$ & Brief introduction & On-going clinical trials \\
\hline $\begin{array}{l}\text { Figure } 2 \\
A-D\end{array}$ & $\begin{array}{l}\text { The Woven } \\
\text { Endo-Bridge } \\
\text { (WEB) }\end{array}$ & $\begin{array}{l}\text { Sequent Medical, Ali- } \\
\text { so Viejo, CA, USA } \\
\text { (http://www.se- } \\
\text { quentmedical.com/ } \\
\text { index.html) }\end{array}$ & $\begin{array}{l}\text { CE Mark } \\
\text { (2011); USA } \\
\text { (investiga- } \\
\text { tional use) }\end{array}$ & $\begin{array}{l}\text { China, clini- } \\
\text { cal trial; Ko- } \\
\text { rea and Ja- } \\
\text { pan, NA }\end{array}$ & $\begin{array}{l}\text { WEB is a self-expanding mesh that can be } \\
\text { introduced into intracranial aneurysms } \\
\text { and cover the neck of the aneurysm, re- } \\
\text { sulting in blood flow disruption, thrombo- } \\
\text { sis, and occlusion. }\end{array}$ & $\begin{array}{l}\text { CLinical Assessment of WEB }{ }^{\circledR} \\
\text { Device in Ruptured aneurYSms } \\
\text { (CLARYS) (NCT02687607) }\end{array}$ \\
\hline $\begin{array}{l}\text { Figure } 2 \\
E_{1} F\end{array}$ & $\begin{array}{l}\text { Medina em- } \\
\text { bolization } \\
\text { device } \\
\text { (MED) }\end{array}$ & $\begin{array}{l}\text { Covidien/eV3, } \\
\text { Medtronic, Dublin, } \\
\text { Ireland (https:// } \\
\text { www.ev3.net/neuro/ } \\
\text { us/) }\end{array}$ & $\begin{array}{l}\text { CE Mark } \\
\text { (2014) }\end{array}$ & NA & $\begin{array}{l}\text { MED is a three-dimensional coil with a } \\
\text { memory shape, comprising a radiopaque } \\
\text { platinum core wire and a braid mesh with } \\
\text { petals shape attached to each loop of the } \\
\text { core wire. }\end{array}$ & $\begin{array}{l}\text { Medina Embolization Device In } \\
\text { Neurovascular Aneurysm Study } \\
\text { (MEDINA) (NCT02982200) }\end{array}$ \\
\hline $\begin{array}{l}\text { Figure } 2 \\
\mathrm{G}, \mathrm{H}\end{array}$ & $\begin{array}{l}\text { Barrel vascu- } \\
\text { lar remodel- } \\
\text { ing device } \\
\text { (VRD) sys- } \\
\text { tem }\end{array}$ & $\begin{array}{l}\text { Medtronic, Minneap- } \\
\text { olis, MN, USA } \\
\text { (https://www.ev3. } \\
\text { net/neuro/us/) }\end{array}$ & $\begin{array}{c}\text { CE Mark } \\
(2013)\end{array}$ & NA & $\begin{array}{l}\text { Barrel is a self-expandable laser-cut stent } \\
\text { with a bulged center section designed to } \\
\text { treat wide-necked bifurcation aneurysms } \\
\text { with a single stent. }\end{array}$ & $\begin{array}{l}\text { The Reverse Barrel }{ }^{\text {TM }} \text { VRD Intra- } \\
\text { cranial Aneurysm Trial (Barrel) } \\
\text { (NCT02125097) }\end{array}$ \\
\hline $\begin{array}{l}\text { Figure } 2 \\
\text { I-L }\end{array}$ & PulseRider & $\begin{array}{l}\text { Pulsar Vascular (Cod- } \\
\text { man Neuro), Los Ga- } \\
\text { tos, CA, USA (http:// } \\
\text { www.pulsarvascular. } \\
\text { com/) }\end{array}$ & $\begin{array}{c}\text { CE Mark } \\
(2013)\end{array}$ & NA & $\begin{array}{l}\text { PulseRider is a self-expanding nitinol im- } \\
\text { plant designed for treating wide-neck an- } \\
\text { eurysms arising at vascular bifurcations. }\end{array}$ & $\begin{array}{l}\text { Adjunctive Neurovascular Sup- } \\
\text { port for Wide-neck Aneurysm } \\
\text { Embolization and Reconstruc- } \\
\text { tion (ANSWER) (NCT02312856) }\end{array}$ \\
\hline $\begin{array}{l}\text { Figure } 2 \\
M, N\end{array}$ & pCONus & $\begin{array}{l}\text { Phenox, Bochum, } \\
\text { Germany (http:// } \\
\text { www.phenox.net/) }\end{array}$ & $\begin{array}{c}\text { CE Mark } \\
(2014)\end{array}$ & NA & $\begin{array}{l}\text { The pCONus is a stent designed to treat } \\
\text { wide-neck intracranial bifurcation aneu- } \\
\text { rysms. }\end{array}$ & $\begin{array}{l}\text { pCONus Treatment of Wide- } \\
\text { Neck Intracranial Aneurysms } \\
\text { (pToWin) (NCT02554708) }\end{array}$ \\
\hline $\begin{array}{l}\text { Figure } 2 \\
0, P\end{array}$ & pCANvas & $\begin{array}{l}\text { Phenox, Bochum, } \\
\text { Germany (http:// } \\
\text { www.phenox.net/) }\end{array}$ & NA & NA & $\begin{array}{l}\text { pCANvas is an evolution of the pCONus, } \\
\text { with additional membrane coverage of } \\
\text { the petals (arrows). }\end{array}$ & NA \\
\hline $\begin{array}{l}\text { Figure } 2 \\
0\end{array}$ & Comaneci & $\begin{array}{l}\text { Rapidmedical, } \\
\text { Yokneam, Israel }\end{array}$ & $\begin{array}{l}\text { CE Mark } \\
(2014)\end{array}$ & NA & $\begin{array}{l}\text { The Comaneci device is a compliant radi- } \\
\text { opaque mesh, comparable to a compliant } \\
\text { balloon in aneurysm coiling, without the } \\
\text { drawback of blocked flow within the par- } \\
\text { ent artery during expansion of the device. }\end{array}$ & NA \\
\hline $\begin{array}{l}\text { Figure } 2 \\
\text { R-T }\end{array}$ & eCLIPs & $\begin{array}{l}\text { Evasc Medical Sys- } \\
\text { tems Corp., Vancou- } \\
\text { ver, BC, Canada } \\
\text { (https://www.evasc. } \\
\text { com/) }\end{array}$ & $\begin{array}{l}\text { CE Mark } \\
\text { (2014); FDA } \\
\text { Designating } \\
\text { Humanitari- } \\
\text { an Use De- } \\
\text { vice (2015) }\end{array}$ & NA & $\begin{array}{l}\text { The eCLIPs is a self-expanding, non-cir- } \\
\text { cumferential device designed for treating } \\
\text { wide-necked bifurcation aneurysms. It } \\
\text { has coil retention and flow-disrupting } \\
\text { functions. }\end{array}$ & $\begin{array}{l}\text { European eCLIPs }{ }^{\text {TM }} \text { Safety, Feasi- } \\
\text { bility and Efficacy Study (EESIS) } \\
\text { (NCT02607501) }\end{array}$ \\
\hline $\begin{array}{l}\text { Figure } 2 \\
\text { U-W }\end{array}$ & $\begin{array}{l}\text { Honeycomb } \\
\text { microporous } \\
\text { covered } \\
\text { stent }\end{array}$ & $\begin{array}{l}\text { Corresponding au- } \\
\text { thor: Yasuhide Na- } \\
\text { kayamany@ncvc. } \\
\text { go.jp }\end{array}$ & NA & $\begin{array}{l}\text { Japan, } \\
\text { clinical trial }\end{array}$ & $\begin{array}{l}\text { The novel honeycomb microporous covered } \\
\text { stents were developed for treating large } \\
\text { or wide-necked cerebral aneurysms, with } \\
\text { the cavernous sinus portion of the inter- } \\
\text { nal carotid and vertebrobasilar arteries as } \\
\text { the target treatment regions. }\end{array}$ & $\begin{array}{l}\text { Safety and Efficacy of Honey- } \\
\text { comb Microporous Covered } \\
\text { Stents (NCVC-CS1) for the } \\
\text { Treatment of Intracranial Aneu- } \\
\text { rysms (NCVC-CS1_UAN) } \\
\text { (NCT02907229) }\end{array}$ \\
\hline
\end{tabular}

CE Mark, European Conformity Mark; FDA, U.S. Food and Drug Administration; NA, not available.

from Korea, China, and Japan were compiled and compared based on similar but differently named administrative bodies and the timelines involved.

We present data on three products that are commonly used in clinical practice, namely Neuroform (Stryker), Enterprise (Codman Neuro), and Pipeline (Medtronic), as examples to compare the timeline for importing and to understand the differences in approval times among the three countries.

\section{Results and discussion}

\author{
Part I. New devices for endovascular treatment of \\ intracranial aneurysms \\ We reviewed only new devices that are conceptually different \\ from those currently being used elsewhere but are not yet \\ available in Korea and found nine such systems: the Woven \\ Endo-Bridge (WEB) for intrasaccular flow disruption, the Medi- \\ na coil system for saccular filling, the Barrel stent, the Pul-
}


seRider, the pCONus and pCONvas for assisted wide-necked bifurcation aneurysm coiling, the Comaneci for temporary remodeling of aneurysm neck, the eCLIPs for physiological remodeling of bifurcation aneurysms, and the honeycomb microporous covered stent for wide-neck aneurysms. Information on each device is listed in Table 1 and depicted in Figure 2. Incidentally, seven of these devices are mainly designed for treating wide-necked bifurcation aneurysms, and the covered stent is recommended for treating side-wall aneurysms.

\section{The WEB ${ }^{T M}$ aneurysm embolization system}

The WEB (Sequent Medical, Aliso Viejo, CA, USA) is a nitinolbased braided-wire intravascular device designed to be used for treating wide-necked bifurcation aneurysms. ${ }^{32}$ It can be introduced into intracranial aneurysms, where it spans the aneurysmal neck to disrupt inflow and reduce intra-saccular flow; thereby, resulting in thrombosis. The smooth and dense surface of the WEB can allow endothelial cells to bridge the neck of the aneurysm and support subsequent vessel wall reconstruction. ${ }^{33}$ The device has been progressively developed from a dual-layer version (WEB-DL) to a single-layer version (WEB-SL) that can be used in cylinder-shaped or sphere-shaped configurations (Figure $2 \mathrm{~A}-\mathrm{D}$ ). ${ }^{23}$

Numerous clinical studies have been designed to investigate the safety and efficacy of the WEB in the treatment of intracranial wide-necked bifurcation aneurysms. ${ }^{23,28,32-35}$ The technical success rate ranged from $92.9 \%$ to $98.7 \%$, adequate occlusion at 1-year ranged from $80 \%$ to $82 \%$, and procedural morbidity ranged from $1.8 \%$ to $2.7 \%$, with no mortalities reported. ${ }^{23,28,32,33,35}$ Thromboembolic events occurred in $4.7 \%$ to $15.6 \%$ of patients, ${ }_{1}^{23,28,32,34,35}$ and adjustment for preoperative and intraoperative antiplatelet treatment showed that the use of any antiplatelet medication was associated with fewer thromboembolic events. ${ }^{23,34}$ Compared with that of the WEB$D L$, the WEB-SL with enhanced visualization showed similar rates for technical success, adequate occlusion at 1 year, and procedural morbidity and mortality. ${ }^{23}$

\section{Medina embolization device}

The Medina embolization device (MED) is a woven cage that reduces flow into the aneurysm, thereby progressively leading to intrasaccular thrombosis. It is a three-dimensional (3D) coil that is linear in its unconstrained state. When the device is deployed within the aneurysm sac, it expands to its $3 D$ spherical shape as the petals unfold to cover the sac wall and the aneurysm neck (Figure $2 \mathrm{E}$ and F). ${ }^{36}$ Blood flow to the aneurysm is disrupted by the woven material that covers the aneurysm neck; thus, the MED is a device that combines the characteris- tics of a neck-bridging device and an intrasaccular flow disrupter. The MED is manipulated and deployed through a 0.021" microcatheter and can be mechanically released.

The first clinical experience with Medina was reported in 2015 in a study ${ }^{36}$ where nine aneurysms in five patients were selected for treatment with the Medina coil system. The study reported improved circumferential aneurysm filling, with fewer devices and faster operating times. ${ }^{36}$ Two more studies reported the use of the Medina device in 15 and 13 aneurysms, respectively, with a technical success rate of $93.3 \%(14 / 15)$ and $100 \%(13 / 13)$, and mid-term occlusion rates of $90.9 \%$ (10/11) and $83.3 \%(10 / 12){ }_{1}^{20,37}$ respectively. These studies also reported that one thromboembolic complication was suspected to be caused by the large surface area of contact between the device covering the aneurysm neck and the parent artery but that the patient recovered from the neurological deficit after a bolus of intravenous aspirin. ${ }^{20}$ As an average of 2.5 deployments was reported for the Medina coil, there is a possibility of thrombus formation during the deployment of multiple Medina coils due to its thrombogenic design. ${ }^{20}$

\section{Barrel vascular remodeling device system}

The use of stent-assisted coiling techniques can be challenging at times due to widening of the vessel lumen, which causes inappropriate abutting of the stent to the vessel wall at the aneurysm level. ${ }^{18}$ The Barrel vascular remodeling device (VRD) is a self-expandable, laser-cut stent that has a bulged center section. It is designed as a single device for stent-assisted coil embolization of wide-necked bifurcation aneurysms to lower the metalto-artery ratio and the inherent risk of thromboembolic complications due to multiple stents (Figure $2 \mathrm{G}$ and $\mathrm{H}$ ). ${ }^{18}$

The initial French Barrel Registry trial study reported a technical success rate of $88.3 \%$ (15/17) with no adverse event. ${ }^{38}$ In another recently published study, 17 patients with wide-necked bifurcation aneurysms underwent stent-assisted coil embolization with Barrel stents with a technical success rate of $94.1 \%$ (16/17). One ischemic event was observed in one patient that did not result in permanent neurological deficits. ${ }^{18}$

\section{The PulseRider}

The PulseRider is another device for treating wide-necked bifurcation aneurysms that are considered challenging to treat. It is available in both " $Y$ " and "T" configurations ${ }^{22}$ and acts as a neck bridge in wide-necked aneurysms while protecting the daughter branches during coil embolization (Figure 2I-L).

The PulseRider has been widely studied for aneurysm management in several clinical trials in Europe, the UK, and the USA. The number of patients enrolled in each study ranged 


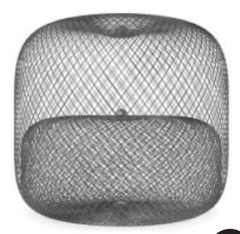

A

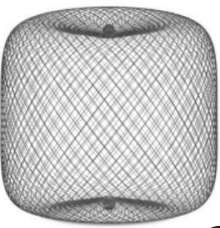

B
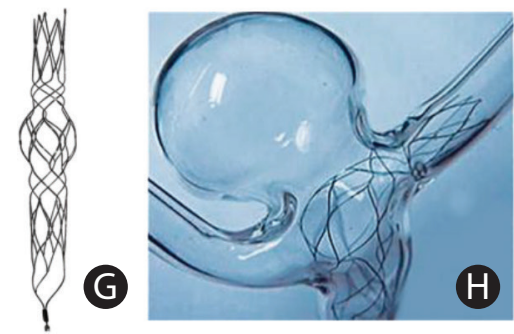

C
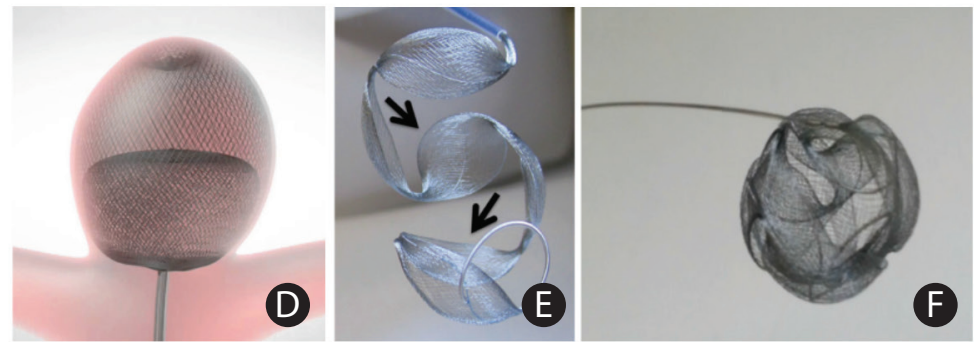

F
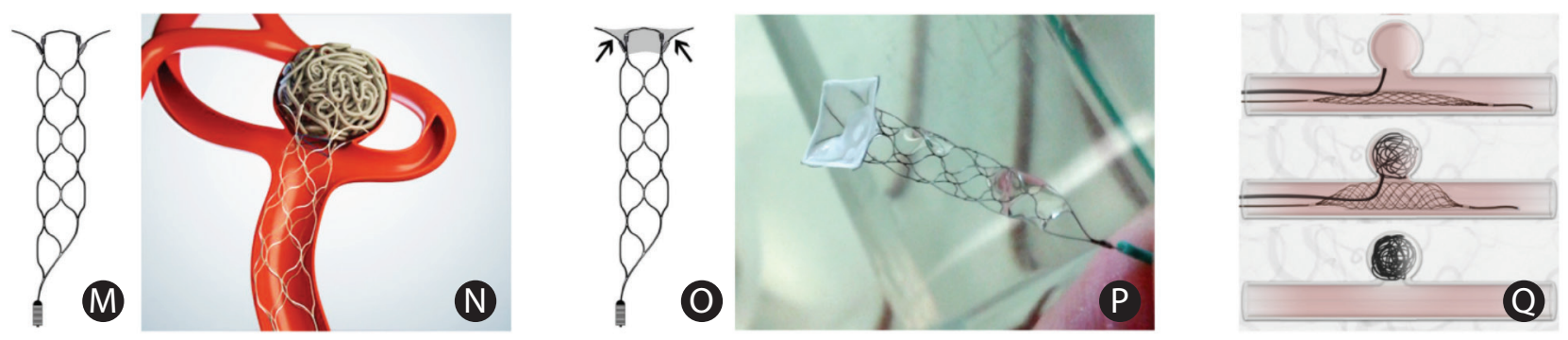
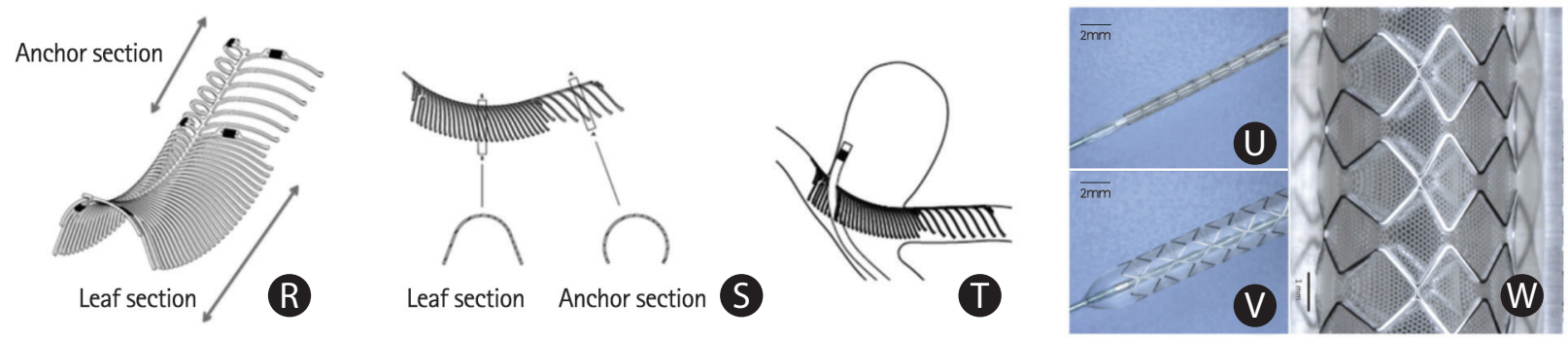

Figure 2. New devices for intracranial aneurysm treatment. (A-D) Woven Endo-Bridge (WEB) devices: (A) a double-layer, (B) a single-layer, and (C) a singlelayer, sphere-shaped WEB device; (D) a WEB double-layer device deployed from a catheter into a bifurcation aneurysm (Copyright Sequent Medical). (E, F) Medina embolization device (MED): (E) deployment of the MED showing the petals of the device (arrows), and (F) fully deployed device showing its three-dimensional conformation (Copyright Medtronic). $(\mathrm{G}, \mathrm{H})$ The Barrel stent device: $(\mathrm{G})$ the original shape of Barrel stent, and $(\mathrm{H})$ the bulged center section of the stent provides complete neck coverage in a flow model (Copyright Medtronic). (I-L) The PulseRider device: (I) "T" configuration, (J) "Y" configuration, (K) view from above; (L) PulseRider deployment at the neck of a bifurcation aneurysm (Copyright Pulsar Vascular). (M, N) The pCONus: (M) the pCONus has a stent-like proximal shaft with four distal petals; $(\mathrm{N})$ the four distal loops of the $\mathrm{pCONus}$ are deployed inside the aneurysm at the neck level, assisting coil occlusion. $(0, \mathrm{P})$ The pCANvas, an evolution of the pCONus with additional membrane coverage of the petals (arrows in 0, Copyright Phenox); ( 0 ) the Comaneci device. The images show the 'deflated' and 'inflated' status of Comaneci, as well as after removal of the device. (R-T) The eCLIPs: (R, S) the eCLIPs device has a leaf section and an anchor section; (T) deployment position of the eCLIPs device, with the leaf section covering the bifurcation aneurysm and allowing microcatheter access to the aneurysm sac (Copyright Evasc Medical Systems Corp.). (U-W) The balloon-expandable honeycomb microporous covered stent crimped on the balloon catheter $(\mathrm{U})$, completely expanded $(\mathrm{V})$, and removed from the catheter $(\mathrm{W})$. Adapted from Nakayama et al., with permission from Springer Nature. ${ }^{45}$ 
from 10 to 34 , the 6-month adequate occlusion rate ranged from $87.9 \%$ to $100 \%$, and only a few device-related complications were reported. ${ }^{22,27,39}$

\section{The $p$ CONus and PCANvas}

The pCONus is a modified stent-like device designed to assist coil packing of wide-necked bifurcation aneurysms. The distal end of the pCONus has four petals and is implanted inside the aneurysm at its neck, whereas the shaft is anchored in the parent vessel (Figure $2 \mathrm{M}$ and $\mathrm{N}$ ).

An initial study reported the experience of treating 28 widenecked aneurysms with pCONus-assisted coiling. ${ }^{40}$ In 25/28 aneurysms, a single pCONus was used for retaining coils inside the aneurysm sac and protecting the efferent vessels. In two patients, another device was necessary to prevent occlusion of the efferent vessels, whereas in one patient, a second pCONus device was necessary to protect the neck region of the aneurysm. No permanent or transient ischemic symptom was observed, and follow-up angiography between 2 to 19 months showed adequate occlusion in 85.3\% patients (19/22). Although a single pCONus cannot be used to resolve all complex wide-necked aneurysms with arteries deriving from the aneurysm fundus, the use of the pCONus in conjunction with the other stents is considered to be a useful combination in such situations. ${ }^{21,41}$

The pCANvas is an evolution of the pCONus, as it has an additional membrane covering the petals that was specifically designed to modify flow into the aneurysm sac, in addition to supporting coiling (Figure 20 and P). An in vitro experiment showed that the intraluminal membrane of the pCANvas strongly reduced intra-aneurysmal flow; ${ }^{40}$ however, we did not find pertinent clinical or human studies.

\section{The Comaneci device}

The Comaneci device is a compliant radiopaque mesh, comparable to a compliant balloon in aneurysm coiling, without the drawback of blocked flow within the parent artery during expansion of the device. Permanent dual antiplatelet therapy is not required since the device is fully removed at the end of the procedure. The extent of expansion can be adjustable by the operator via a slider at the handle (Figure 20). ${ }^{42}$

The initial experience with Comaneci in the treatment of wide-necked aneurysms showed a technical success rate of $77.8 \%(14 / 18)$. One clinically relevant complication (a thrombotic occlusion of the target internal carotid artery) was reported (5.6\%), which might be caused by device-related dissection. ${ }^{42}$

\section{The eCLIPS}

The eCLIPs was developed as an endovascular clipping device specifically designed to treat bifurcation aneurysms. The eCLIPS has two discrete sections: an anchor segment designed to conform to the architecture of the arterial walls beside the neck of the bifurcation aneurysm and a leaf segment with movable ribs designed to allow a coil delivery catheter to pass through the implanted device to deliver detachable coils. The leaf segment can also be used to divert blood flow and reduce the jet effect into the aneurysm, thus reducing the chances of aneurysm recurrence. ${ }^{19}$ The first generation eCLIPs was launched in $2008 .{ }^{43}$ The second-generation eCLIPs showed definitive and sustained aneurysm exclusion from circulation and device incorporation into the vessel wall to produce physiological remodeling of the aneurysm during preclinical assessment. ${ }^{44} \mathrm{~A}$ video of the deployment process can be accessed at https://vimeo. com/191976808 (Figure 2R-T).

The second-generation eCLIPs was tested in patients for treating wide-necked aneurysms. ${ }^{44}$ In an initial clinical series, successful placement of an eCLIPs was achieved in 76\% (25/33) of the patients, with an aneurysm occlusion rate of $81.0 \%$ (17/21). However, as the delivery method of the eCLIPs is unique, the learning curve showed that successful placement of an eCLIPs requires considerable practice. ${ }^{44}$ Furthermore, despite the use of dual antiplatelet therapy, two periprocedural transient ischemic attacks and two asymptomatic thrombotic events occurred in this study involving 25 patients. ${ }^{44}$

\section{The honeycomb microporous covered stent}

The novel honeycomb microporous covered stent was developed for treating large or wide-necked cerebral aneurysms. The balloon-expandable stents are covered with a polyurethane film, and the film acquires a honeycomb pattern after expansion (pore diameter of $<100 \mu$, opening area of $>30 \%$ ). The target treatment regions for its clinical application includes the cavernous sinus portion of the internal carotid and the vertebrobasilar arteries. In animal experiments, these stents showed excellent embolization performance at the aneurysm without disturbing branching flow. ${ }^{45}$ An investigator-initiated, first-inhuman, clinical trial of the covered stents is currently underway (NCT02907229, Clinical Trials.gov) (Figure 2U-W).

\section{Part II. Regulatory processes for high-risk medical devices}

Medical devices are classified into several categories depending on their degree of invasiveness in the human body. This classification also varies by countries because of differences in regulation policies. Current classifications of medical devices in Korea, China, and Japan are listed and compared in Figure 3. All devices reviewed in this study are categorized as high-risk 


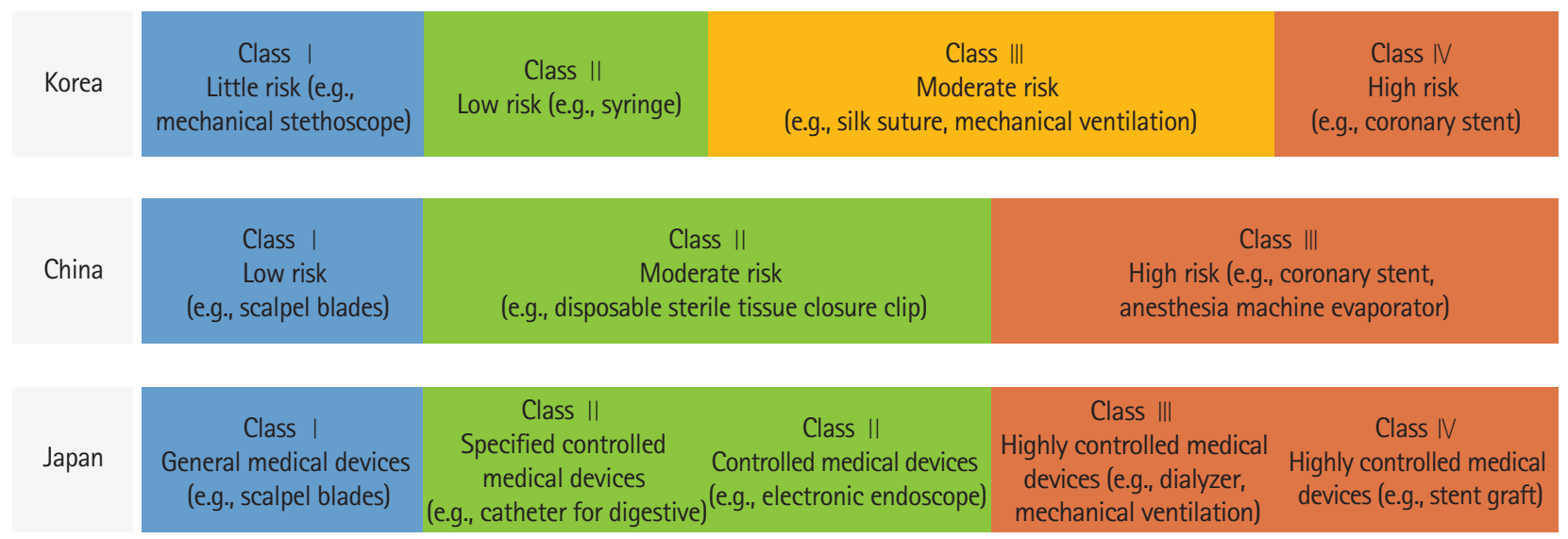

Figure 3. Medical device classification in Korea, China, and Japan.

intravascular devices (as defined by FDA) ${ }^{46}$ and belong to class III/IV in Korea, Class III in China, and Class IV in Japan. ${ }^{30,47-49}$

\section{Korea}

In Korea, the MFDS is in charge of approving high-risk devices (Figure $4 \mathrm{~A})^{30}$ and clinical study reports are an essential requirement for technical safety and effectiveness review. If the clinical study reports from other countries comply with MFDS criteria, a Korean clinical study is not required..$^{25}$ Applications for reimbursement cost and coverage of a medical device should be submitted to the Ministry of Health and Welfare (MOHW) within 30 days of regulatory approval by the MFDS. ${ }^{30}$ The Health Insurance Review and Assessment Services reviews these applications and provides recommendations to the MOHW, which then decides on reimbursement coverage and price. ${ }^{50,51}$ Importantly, devices that do not get approval for reimbursement are generally not allowed to be used in hospitals. Therefore, the potential risk for companies is that although they may have MFDS approval, cost reimbursement can be denied by the MOHW. ${ }^{52}$

As per the MFDS website, the registration process for MFDS approval takes $<142$ workdays $(55+77+10)$, whereas reimbursement approval takes $<150$ days (Figure 4A). However, the actual time taken, including the time for response-to-deficiency letter, vacations, safety, and effectiveness review, is much longer ${ }_{1}^{30}$ especially for novel-design devices because they need additional approval from the National Evidence-based Healthcare Collaborating Agency (NECA) (Figure 4A). ${ }^{53}$ Taking the Pipeline device (an embolization device for large intracranial aneurysm) as an example, we found that the even though the MFDS had given its approval in May 2011, the NECA issued its approval for the new device in October 2012, and the MOHW finally approved its reimbursement in October 2014 (Figure 5). In this process, the implementation of stricter regulations aimed to evaluate the potential benefits and harms of new devices, and to reduce the incidence of safety issue in the future.

\section{China}

In China, all class III medical devices should be approved by the CFDA (Figure 4B). ${ }^{13}$ The Center for Medical Device Evaluation (CMDE) is responsible for conducting a dossier review during the medical device registration process, ${ }^{13}$ but most class III devices require clinical trials. ${ }^{27}$ The application for a clinical trial should be initially submitted to the CFDA, and the clinical trial will be conducted in two or more "National Drug Clinical Study Sites. ${ }^{127}$ According to the instructions for clinical trials given by the CFDA, the clinical trial should take at least 9 months, including application time and license registration with the CFDA. ${ }^{13}$ However, according to the experience of medical device companies, the entire process, including clinical trial time and application for CFDA license, usually took approximately 3 years. Thus, there seems to be a wide time-lapse between license application and final permission. Once a device gets the CFDA license and permission for sale from the local Commission of Health and Family Planning, it can be introduced into hospitals for clinical use with or without reimbursement (Figure 4B). ${ }^{54}$

\section{Japan}

Registration of medical devices in Japan generally takes 1 to 3 years depending on device classification. ${ }^{29}$ Device regulation in Japan is centrally conducted by the PMDA and the Ministry of Health, Labour and Welfare (MHLW) (Figure 4C). ${ }^{31}$ The MHLW authorizes new device approvals upon PMDA analysis, which include site inspections and a pre-market review of the new 

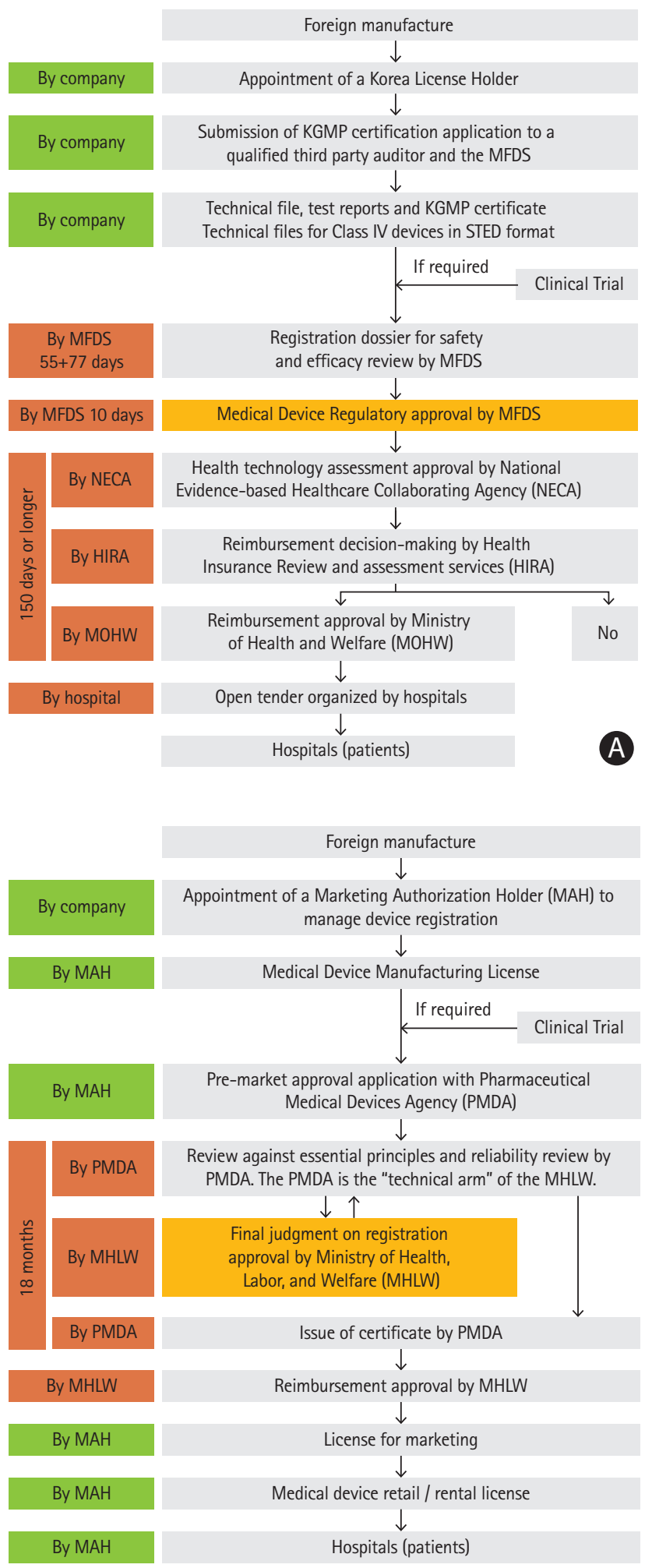

C

technology. A foreign manufacturer has to appoint a Marketing Authorization Holder (MAH), and the MAH files a pre-market approval application with the PMDA to ultimately obtain approval from the MHLW. ${ }^{31}$ Only local companies in Japan with a

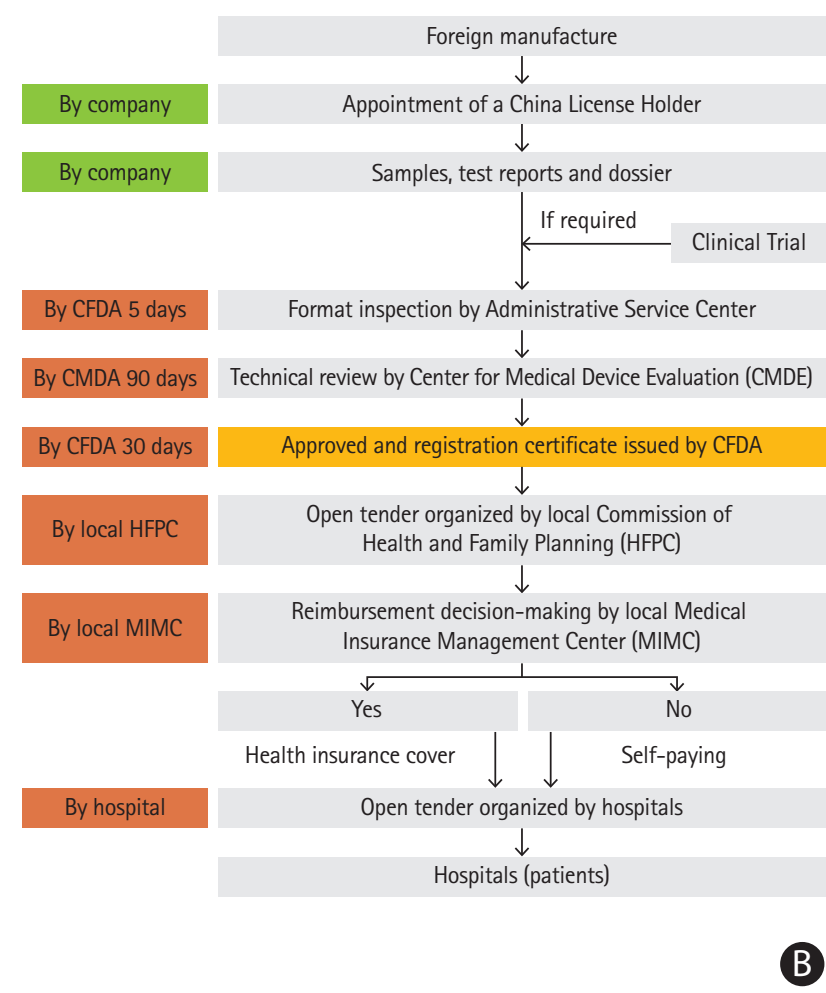

Figure 4. The regulatory process for foreign medical devices in (A) Korea, (B) China, and (C) Japan. KGMP, Korean Good Manufacturing Practices; MFDS, Ministry of Food and Drug Safety; STED, Summary Technical Documentation; NECA, National Evidence-based Healthcare Collaborating Agency; HIRA, Health Insurance Review and Assessment Agency; MOHW, Ministry of Health and Welfare; CFDA, China Food and Drug Administration; CMDE, Center for Medical Device Evaluation; HFPC, Commission of Health and Family Planning; MIMC, Medical Insurance Management Center; MAH, Marketing Authorization Holder; PMDA, Pharmaceuticals and Medical Devices Agency; MHLW, Ministry of Health, Labour and Welfare.

valid MAH license can import and sell medical products in the Japanese market. Japan requires clinical trials for most new and improved medical devices to be conducted in the Japanese population. ${ }^{26}$ Nevertheless, the PMDA often accepts the results 


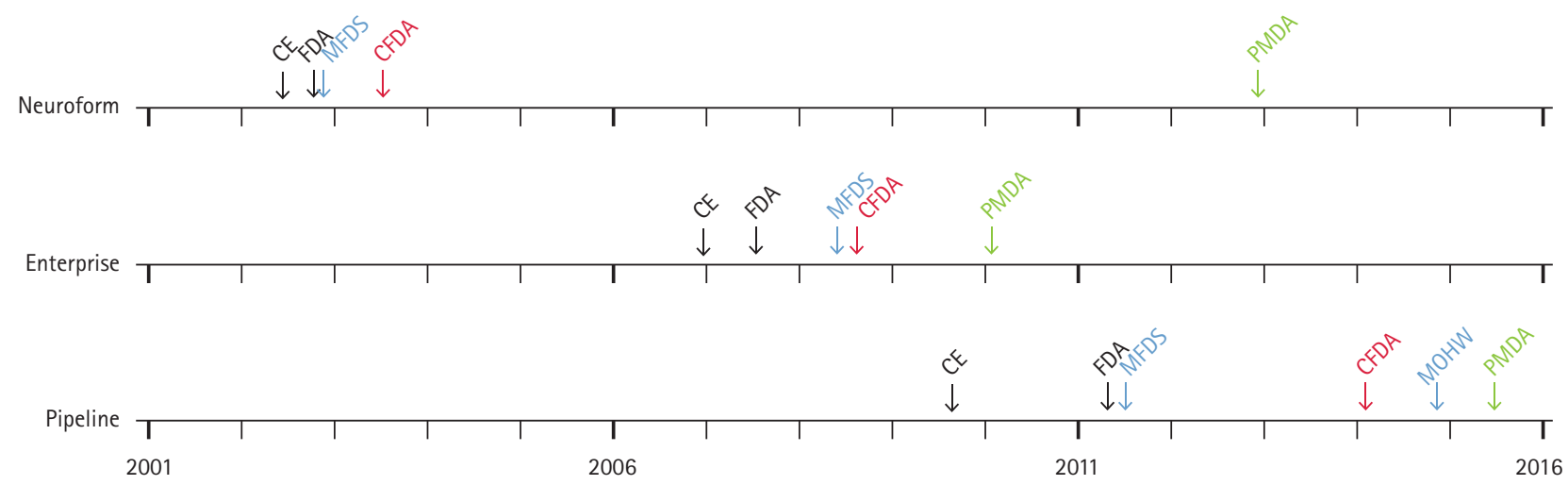

Figure 5. Timeline of regulatory process for representative medical devices from Neuroform, Enterprise, and Pipeline in Korea (blue), China (red), and Japan (green). During the period between Neuroform and Pipeline approvals, the processing time for permission increased in Korea. Note the two-step approval process in Korea for the Pipeline as a new device: first by the Ministry of Food and Drug Safety (MFDS) and next by the Ministry of Health and Welfare (MOHW). The reason of import delay for Neuroform in Japan was that Neuroform EZ, the fourth generation device, was first introduced in Japan. Such time delay may also be due to cost differences among countries; Neuroform and Enterprise cost approximately 1,400 USD in Korea, 4,000 USD in China, and 4,200 USD in Japan, whereas the Pipeline costs 9,000 USD in Korea, 13,000 USD in China, and 13,900 USD in Japan. CE, Conformité Européenne (European Conformity); FDA, U.S. Food and Drug Administration; CFDA, China Food and Drug Administration; PMDA, Pharmaceuticals and Medical Devices Agency.

of clinical trials conducted outside Japan if the investigation conforms to Japan's Good Clinical Practices. ${ }^{26}$ The time for regulatory approval takes usually 9 to 18 months based on PMDA website (Figure 4C). ${ }^{29}$

\section{Conclusions}

New and innovative endovascular devices facilitate the management of difficult aneurysms and improve clinical outcomes. Although time span between the appearances of new devices is getting shorter worldwide, the possible benefits from fast introduction of devices must be carefully weighed against the risks arising from them as well. Reasonable communication among the appropriate government authorities, manufacturers, and the related medical societies may improve the registration process and reduce safety issue of devices in the future.

\section{Disclosure}

The authors have no financial conflicts of interest.

\section{Acknowledgments}

We would like to thank Miri Kim and Min Jung Kim from Medtronic (Korea), Yang Cai from Medtronic (China), and Juan Shang from Codman Neuro (China) for their verification and expert advice on the regulatory process.

\section{References}

1. Brown RD Jr, Broderick JP. Unruptured intracranial aneurysms: epidemiology, natural history, management options, and familial screening. Lancet Neurol 2014;13:393-404.

2. Bor AS, Rinkel GJ, van Norden J, Wermer MJ. Long-term, serial screening for intracranial aneurysms in individuals with a family history of aneurysmal subarachnoid haemorrhage: a cohort study. Lancet Neurol 2014;13:385-392.

3. Guglielmi G, Viñuela F, Duckwiler G, Dion J, Lylyk P, Berenstein $A$, et al. Endovascular treatment of posterior circulation aneurysms by electrothrombosis using electrically detachable coils. J Neurosurg 1992;77:515-524.

4. Molyneux A, Kerr R, Stratton I, Sandercock P, Clarke M, Shrimpton J, et al. International Subarachnoid Aneurysm Trial (ISAT) of neurosurgical clipping versus endovascular coiling in 2143 patients with ruptured intracranial aneurysms: a randomised trial. Lancet 2002;360:1267-1274.

5. Molyneux AJ, Kerr RS, Yu LM, Clarke M, Sneade M, Yarnold $J A$, et al. International subarachnoid aneurysm trial (ISAT) of neurosurgical clipping versus endovascular coiling in 2143 patients with ruptured intracranial aneurysms: a randomised comparison of effects on survival, dependency, seizures, rebleeding, subgroups, and aneurysm occlusion. Lancet 2005;366:809-817.

6. Wiebers D0, Whisnant JP, Huston J 3rd, Meissner I, Brown RD Jr, Piepgras DG, et al. Unruptured intracranial aneurysms: natural history, clinical outcome, and risks of surgical and endovascular treatment. Lancet 2003;362:103-110. 
7. Huang MC, Baaj AA, Downes $K_{1}$ Youssef AS, Sauvageau $E_{1}$ van Loveren HR, et al. Paradoxical trends in the management of unruptured cerebral aneurysms in the United States: analysis of nationwide database over a 10-year period. Stroke 2011;42:1730-1735.

8. Alshekhlee A, Mehta S, Edgell RC, Vora N, Feen E, Mohammadi $A$, et al. Hospital mortality and complications of electively clipped or coiled unruptured intracranial aneurysm. Stroke 2010;41:1471-1476.

9. Chang HW, Shin SH, Suh SH, Kim BS, Rho MH. Cost-effectiveness analysis of endovascular coiling versus neurosurgical clipping for intracranial aneurysms in Republic of Korea. Neurointervention 2016;11:86-91.

10. Dumont TM, Eller JL, Mokin M, Sorkin GC, Levy El. Advances in endovascular approaches to cerebral aneurysms. Neurosurgery 2014;74 Suppl 1:S17-S31.

11. Henkes $H$, Weber W. The past, present and future of endovascular aneurysm treatment. Clin Neuroradiol 2015;25 Suppl 2:317-324.

12. Thompson BG, Brown RD Jr, Amin-Hanjani S, Broderick JP, Cockroft KM, Connolly ES Jr, et al. Guidelines for the management of patients with unruptured intracranial aneurysms: a guideline for healthcare professionals from the American Heart Association/ American Stroke Association. Stroke 2015;46:2368-2400.

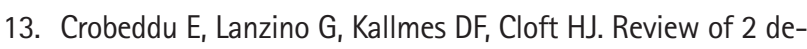
cades of aneurysm-recurrence literature, part 1: reducing recurrence after endovascular coiling. AJNR Am J Neuroradiol 2013;34:266-270.

14. Crobeddu E, Lanzino G, Kallmes DF, Cloft HJ. Review of 2 decades of aneurysm-recurrence literature, part 2: managing recurrence after endovascular coiling. AJNR Am J Neuroradiol 2013;34:481-485.

15. Colby GP, Lin LM, Caplan JM, Jiang B, Michniewicz B, Huang $J$, et al. Flow diversion of large internal carotid artery aneurysms with the surpass device: impressions and technical nuance from the initial North American experience. J Neurointerv Surg 2016;8:279-286.

16. Shapiro M, Raz E, Becske T, Nelson PK. Variable porosity of the pipeline embolization device in straight and curved vessels: a guide for optimal deployment strategy. AJNR Am J Neuroradiol 2014;35:727-733.

17. Luecking $H$, Engelhorn $T$, Lang $S$, Goelitz $P$, Kloska $S$, Roessler $K$, et al. FRED flow diverter: a study on safety and efficacy in a consecutive group of 50 patients. AJNR Am J Neuroradiol 2017;38:596-602.

18. Mühl-Benninghaus R, Simgen A, Reith W, Yilmaz U. The Barrel stent: new treatment option for stent-assisted coiling of wide-necked bifurcation aneurysms-results of a single-cen- ter study. J Neurointerv Surg 2017;9:1219-1222.

19. Marotta TR, Riina HA, McDougall I, Ricci DR, Killer-Oberpfalzer M. Physiological remodeling of bifurcation aneurysms: preclinical results of the eCLIPs device. J Neurosurg. 2017 Mar 17 [Epub]. https://doi.org/10.3171/2016.10.JNS162024.

20. Sourour NA, Vande Perre S, Maria FD, Papagiannaki C, Gabrieli J, Pistocchi $S$, et al. Medina(R) embolization device for the treatment of intracranial aneurysms: safety and angiographic effectiveness at 6 months. Neurosurgery. 2017 Apr 10 [Epub]. https://doi.org/10.1093/neuros/nyx161.

21. Aguilar-Pérez $M$, Kurre $W$, Fischer $S$, Bäzner $H$, Henkes $H$. Coil occlusion of wide-neck bifurcation aneurysms assisted by a novel intra- to extra-aneurysmatic neck-bridging device (pCONus): initial experience. AJNR Am J Neuroradiol 2014;35:965971.

22. Spiotta AM, Derdeyn CP, Tateshima S, Mocco J, Crowley RW, Liu KC, et al. Results of the ANSWER trial using the PulseRider for the treatment of broad-necked, bifurcation aneurysms. Neurosurgery 2017;81:56-65.

23. Pierot L, Gubucz I, Buhk JH, Holtmannspotter M, Herbreteau $D$, Stockx $L$, et al. Safety and efficacy of aneurysm treatment with the WEB: results of the WEBCAST 2 study. AJNR Am J Neuroradiol 2017;38:1151-1155.

24. Hwang TJ, Sokolov E, Franklin JM, Kesselheim AS. Comparison of rates of safety issues and reporting of trial outcomes for medical devices approved in the European Union and United States: cohort study. BMJ 2016;353:i3323.

25. Pacific Bridge Medical. Medical Device Registration in Korea. http://www.pacificbridgemedical.com/regulatory-services/ medical-device/product-registration/korea/. Accessed January 5, 2018.

26. Pacific Bridge Medical. Medical Device Registration in Japan. http://www.pacificbridgemedical.com/regulatory-services/ medical-device/product-registration/japan/. Accessed January 5, 2018.

27. Gory B, Spiotta AM, Di Paola F, Mangiafico S, Renieri L, Consoli $A$, et al. PulseRider for treatment of wide-neck bifurcation intracranial aneurysms: 6-month results. World Neurosurg 2017;99:605-609.

28. Fiorella D, Molyneux A, Coon A, Szikora I, Saatci I, Baltacioglu $F$, et al. Demographic, procedural and 30-day safety results from the WEB Intra-saccular Therapy Study (WEB-IT). J Neurointerv Surg 2017;9:1191-1196.

29. Emergo. PMDA medical device registration and approval in Japan. https://www.emergogroup.com/services/japan/pmdamedical-device-registration-approval-process. Accessed January 5, 2018.

30. Ministry of Food and Drug Safety. Medical device approval 
process in Korea. https://www.mfds.go.kr/eng/index. do?nMenuCode=114. Accessed January 5, 2018.

31. Pharmaceuticals and Medical Devices Agency. Japanese approval system for pharmaceuticals/medical devices. https:// www.pmda.go.jp/english/review-services/outline/0001.html. Accessed January 5, 2018.

32. Mine B, Goutte A, Brisbois D, Lubicz B. Endovascular treatment of intracranial aneurysms with the Woven EndoBridge device: mid term and long term results. J Neurointerv Surg. 2017 Feb 20 [Epub]. https://doi.org/10.1136/neurintsurg-2016-012964.

33. Asnafi $S$, Rouchaud $A$, Pierot $L$, Brinjikji W, Murad $\mathrm{MH}_{1}$ Kallmes DF. Efficacy and safety of the Woven EndoBridge (WEB) device for the treatment of intracranial aneurysms: a systematic review and meta-analysis. AJNR Am J Neuroradiol 2016;37:2287-2292.

34. Pierot L, Spelle L, Molyneux A, Byrne J; WEBCAST and French Observatory Investigators. Clinical and anatomical follow-up in patients with aneurysms treated with the WEB device: 1-year follow-up report in the cumulated population of 2 prospective, multicenter series (WEBCAST and French Observatory). Neurosurgery 2016;78:133-141.

35. Lawson A, Molyneux A, Sellar R, Lamin S, Thomas A, Gholkar A, et al. Safety results from the treatment of 109 cerebral aneurysms using the Woven EndoBridge technique: preliminary results in the United Kingdom. J Neurosurg 2018;128:144-153.

36. Turk AS, Maia O, Ferreira CC, Freitas D, Mocco J, Hanel R. Periprocedural safety of aneurysm embolization with the Medina Coil System: the early human experience. J Neurointerv Surg 2016;8:168-172.

37. Aguilar Perez $M$, Bhogal $P$, Martinez Moreno $R$, Bäzner $H$, Ganslandt O, Henkes H. The Medina Embolic Device: early clinical experience from a single center. J Neurointerv Surg 2017;9:77-87.

38. Piotin M, Blanc R, Berge J, Turjman F. The barrel vascular reconstruction device for the treatment of wide-neck bifurcation aneurysms. Stroke 2015;46 Suppl 1:AWP86.

39. Spiotta AM, Chaudry MI, Turk AS, Turner RD. Initial experience with the PulseRider for the treatment of bifurcation aneurysms: report of first three cases in the USA. J Neurointerv Surg 2016;8:186-189.

40. Pérez MA, Henkes $H$, Bouillot $P$, Brina O, Slater LA, Pereira VM. Intra-aneurysmal hemodynamics: evaluation of pCONus and pCANvas bifurcation aneurysm devices using DSA optical flow imaging. J Neurointerv Surg 2016;8:1197-1201.

41. Bhogal $P$, Aguilar Perez $M$, Aguilar Pérez R, Miś $M$, Miś $M$, Henkes H. Combined use of a pCONus and a Solitaire stent: report of two cases. Interv Neuroradiol 2017;23:123-128.
42. Fischer S, Weber A, Carolus A, Drescher F, Götz F, Weber W. Coiling of wide-necked carotid artery aneurysms assisted by a temporary bridging device (Comaneci): preliminary experience. J Neurointerv Surg 2017;9:1039-1097.

43. Marotta TR, Gunnarsson T, Penn I, Ricci DR, McDougall I, Marko A, et al. A novel endovascular clip system for the treatment of intracranial aneurysms: technology, concept, and initial experimental results. Laboratory investigation. J Neurosurg 2008;108:1230-1240.

44. Chiu AH, De Vries J, O'Kelly CJ, Riina H, McDougall I, Tippett J, et al. The second-generation eCLIPs Endovascular Clip System: initial experience. J Neurosurg. 2017 Mar 17 [Epub]. https://doi.org/10.3171/2016.10.JNS161731.

45. Nakayama $Y$, Satow $T$, Funayama M, Moriwaki T, Tajikawa $T$, Furukoshi $M$, et al. Construction of 3 animal experimental models in the development of honeycomb microporous covered stents for the treatment of large wide-necked cerebral aneurysms. J Artif Organs 2016;19:179-187.

46. Rome BN, Kramer DB, Kesselheim AS. Approval of high-risk medical devices in the US: implications for clinical cardiology. Curr Cardiol Rep 2014;16:489.

47. Petersen M. Specially know how to determine the classification of medical devices in china. https://www.slideshare.net/ CIRSEdwin/specially-know-how-to-determine-the-classification-of-medical-devices-in-china. Accessed January 5, 2018.

48. China Medical Device Regulatory Database. Medical Devices Classification Search System. http://cmdrd.cirs-md.com/. Accessed January 5, 2018.

49. Pharmaceuticals and Medical Devices Agency. Basic concept for approval and certification for medical devices. http:// www.std.pmda.go.jp/scripts/stdDB/pubeng/stdDB_pubeng_ regulation.cgi. Accessed January 5, 2018.

50. Clary N. Kobridge medical devices registration in South Korea. https://www.slideshare.net/kobridge/kobridge-koreanregulation-training. Accessed January 5, 2018.

51. Morulaa HealthTech. The overall process of registration in South Korea by MFDS. http://www.morulaa.com/korea-ministry-offood-and-drug-safety-mfds/. Accessed January 5, 2018.

52. Lee SS, Salole E. Medical device reimbursement coverage and pricing rules in Korea: current practice and issues with access to innovation. Value Health 2014;17:476-481.

53. National Evidence-based Healthcare Collaborating Agency. The list of organization and support of NECA. http://neca. re.kr/eng/introduce/chart.jsp. Accessed January 5, 2018.

54. Kramer DB, Tan YT, Sato C, Kesselheim AS. Ensuring medical device effectiveness and safety: a cross: national comparison of approaches to regulation. Food Drug Law J 2014;69:1-23. 